\title{
Promoting the Practical Ability of Chinese Students by the Virtual Simulation Experiment
}

\author{
Xianghe Ren1, Qi Yang1, Jiancai Leng1, Jinhong Li² \\ ${ }^{1}$ International School for Optoelectronic Engineering, Qilu University of Technology (Shandong Academy of Sciences), Jinan, \\ China \\ ${ }^{2}$ School of Mathematics and Statistics, Qilu University of Technology (Shandong Academy of Sciences), Jinan, China \\ Email: xhren101@qlu.edu.cn, shanshiyangqi@126.com, jiancaileng@qlu.edu.cn, lijinhong@qlu.edu.cn
}

How to cite this paper: Ren, X. H., Yang, Q., Leng, J. C., \& Li, J. H. (2022). Promoting the Practical Ability of Chinese Students by the Virtual Simulation Experiment. Creative Education, 13, 484-490. https://doi.org/10.4236/ce.2022.132028

Received: January 8, 2022

Accepted: February 13, 2022

Published: February 16, 2022

Copyright (c) 2022 by author(s) and Scientific Research Publishing Inc. This work is licensed under the Creative Commons Attribution International License (CC BY 4.0).

http://creativecommons.org/licenses/by/4.0/

\begin{abstract}
In this paper, we analyze the necessity of developing virtual simulation experiment basing on the computer technology by taking the optical cold processing as an example. For the traditional experiment teaching, the teachers mainly focus on showing how to operate experiment equipment. It is difficult to carry out innovative experiments and keep up with the step of new engineering construction and teaching reform. With the development of computer technology, the Virtual reality (VR) technology, which solves the invisibility problem, plays an important role in teaching. Our optical cold processing teaching system, which is designed on the basis of Virtual reality (VR) technology, integrates several experiments. This teaching system can fully be shared by long-range control and has more help to promote student's practical ability. According to the teaching situation for several semesters, the teaching effect is better than that for traditional experiment teaching. The virtual simulation experiments should be popularized.
\end{abstract}

\section{Keywords}

Optical Cold Processing, Computer Technology, Virtual Simulation, Virtual Reality (VR) Technology

\section{Introduction}

The rapid development of computer technology had made it much easier to life and work, such as artificial intelligence diagnosis, intelligent identification, computer network technologies (Chen et al., 2018; Iwagami et al., 2021; Salto-Tellez et al., 2019). In the field of the computer assisted instruction (CAI) (Zheng et al., 2018; Notaroš et al., 2019), the computer technology has also played a very im- 
portant role. The first reason is that the communication and interaction between teachers and students becomes more convenient. The second reason is that it enriches the ways of teachers' teaching and students' learning. The third reason is that in some underdeveloped areas, the teaching and learning resources are very lack, especially the very valuable instruments and equipment, but under the help of CAI the shortage of teaching and learning resources can be made up to a certain degree. The fourth reason is that it makes the teaching and learning not to be limited in time and space.

Basing on the computer technology, a virtual environment including threedimensional (3D) information has grown in 1980s. In 2000, Wenli Cai (Cai et al., 2000) had published a paper entitled "Collaborative Virtual Simulation Environment for Radiotherapy Treatment Planning", in which the Virtual Simulation of radiotherapy treatment planning replaces the real Simulator machine. In 2020, Yang Shen and his coworkers (Shen et al., 2020) have analyzed the cognitive internet of things and propose a Soft K-Means Fuzzy Clustering approach, and they have also demonstrated the ability of artificial intelligence to enhance the communication skills of multi-robot teams.

For photoelectric information science and engineering, the experiment teaching is very important, because the experiment teaching can enhance students' practical ability (Zhao \& Zhao 2019; Yu et al., 2021). In order to promote the practical ability, we design a virtual simulation experiment, which is a high-risk, high-consumption and long-term experiment and is very dangerous to students. By this virtual simulation experiment, the student can experience the actual experiment operation process to enhance their practical ability. In China, there are some less-developed regions, where the teaching resources are not adequate. But in China, the network technology is developing rapidly. China is so far ahead in the coverage model for $5 \mathrm{G}$, which can accelerate development of digital services. The students in less-developed regions can share the advanced teaching resources by this virtual simulation experiment using $5 \mathrm{G}$ technology.

\section{Necessity of Designing the Virtual Simulation Experiment}

The virtual simulation experiment is a catalyst for teaching and learning, and it can help student to sum up some real-processing experience. According to the research results (Davis, 2015), the virtual simulation learning can enhance learning effect and the virtual simulation learning drives greater retention than the other learning methods, as shown in Figure 1 (Davis, 2015; Krathwohl, 2002).

For the traditional experiment teaching, the teachers mainly focus on the demonstration. It is difficult to carry out the innovative experiments. The optical cold processing means that from the large billet supplied by the glass factory to the end of final finished products, the full processing is carried out at room temperature. The whole instruments for the optical cold processing are very expensive, and need large experiment room. At same time, if the students really 


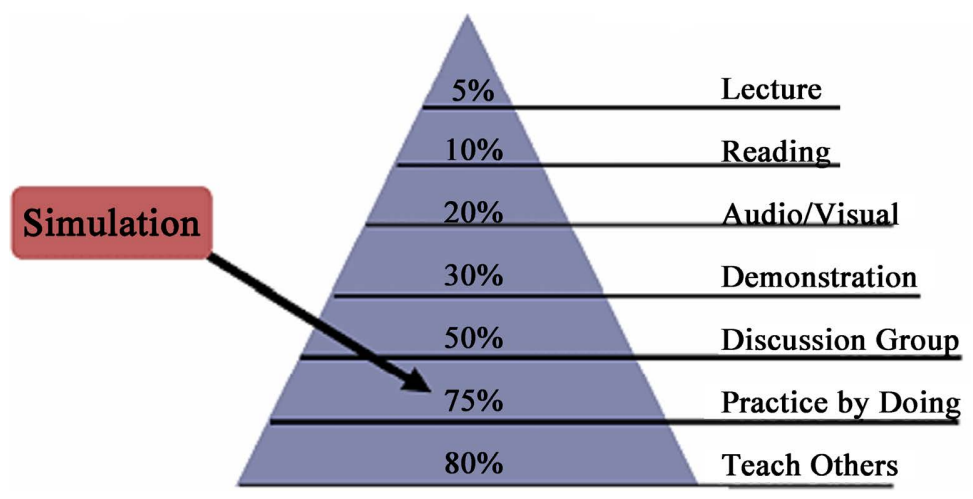

Figure 1. Learning pyramid (Davis, 2015; Krathwohl, 2002).

operate this experiment, it will take a long time and is dangerous to them. So the optical cold processing experiment is canceled by many universities or only is demonstrated to students. It is difficult to keep up with the step of new engineering construction and teaching reform. Under this background we design this virtual simulation teaching system, by which the students can finish the high consumption, irreversible operation, and large-scale comprehensive training.

\section{Overall Structure Design of the Virtual Simulation Experiment}

The optical cold processing simulation experiment teaching system consists of four modules: preview module, experiment module, help module and the evaluation of experiment results module. The schematic diagram of the overall design framework of optical cold processing system is shown in Figure 2. From Figure 2 , we can see that every step is the foundation of the next step, and when the step is finished, the result will be automatically evaluated by this system and the score will be outputed. If the score is located in $60-75$, it is good. If the score is located in $76-90$, it is better. If the score is located in $91-100$, it is best. The students, who have gotten score greater than 60 , can go on the next step. During making experiment, if the students have any difficulty, they can ask for help from the help module. The whole software systems are installed in Web Server Clusters at Qilu University of Technology. The students and other users can enter the Virtual simulation system by Zhi Hui Shu, which is a teaching platform, and make the experiments by the remote control. In the experiment module, there are several specific experiment projects. We take two experiments as examples to show in the following section.

\subsection{Experiment Module I-Cutting Glass}

The cutting glass is the first step for the whole experiment module. In this step, the students can know how to determine the size, thickness according to the target optics device, deeply understand the basic ways of cutting glass, to enrich their imagination and understanding, and further stimulate their innovative ability. In this processing, four subsections are designed: Preparing materials, 


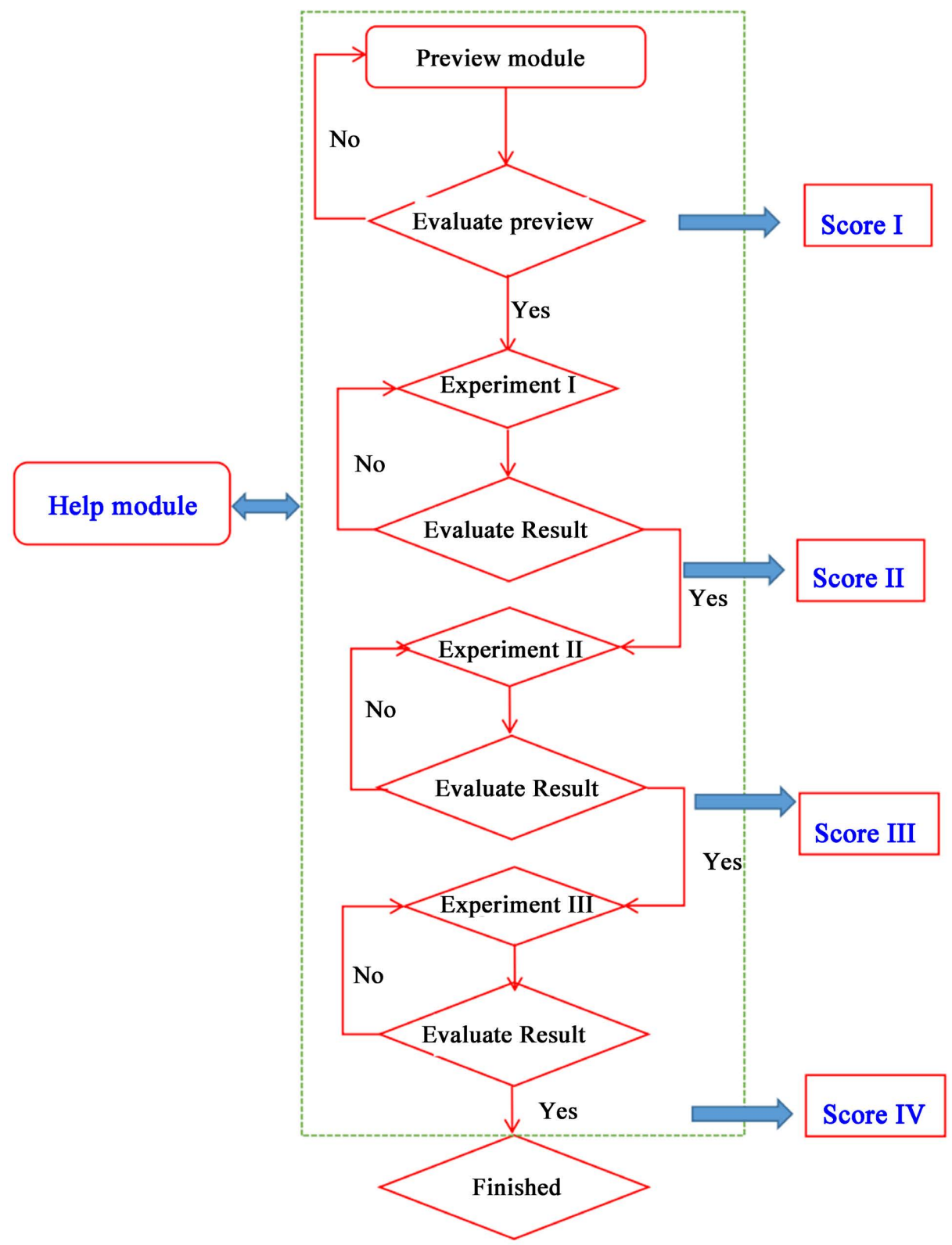

Figure 2. Schematic diagram of the overall design framework of optical cold processing system.

Safety precautions, Adjust instruments and equipment, Automatic cutting. In Figure 3, the control panel of the whole optical cold processing virtual Simulation system is shown. Firstly, the students should set the parameters, such as the size and thickness of glass. Second, the students should adjust the equipments by the control panel. Thirdly, the students start the automatic cutting button. And then the virtual device will finish the cutting process as shown in Figure 4.

\subsection{Experiment Module II-Rolling Virtual Simulation Training}

In this module, the students should polish the cutted glass, and make the glass to change into the optical lens with suitable diameter. For optical lens, there are strict requirements for size, and the error should be as small as possible. The 


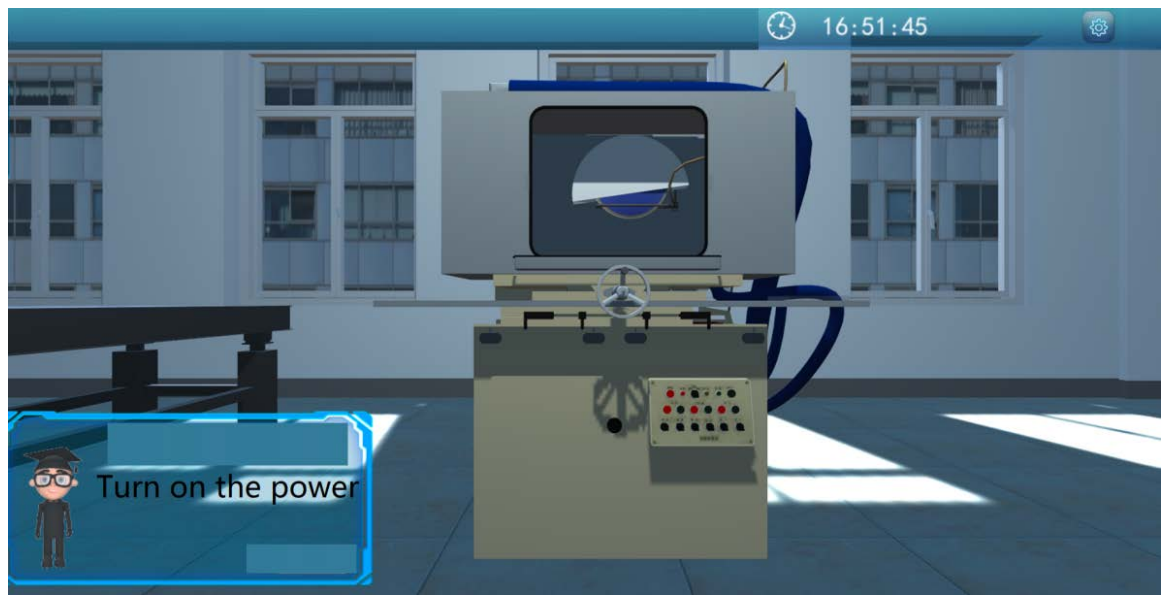

Figure 3. The control panel of the whole optical cold processing virtual Simulation system.

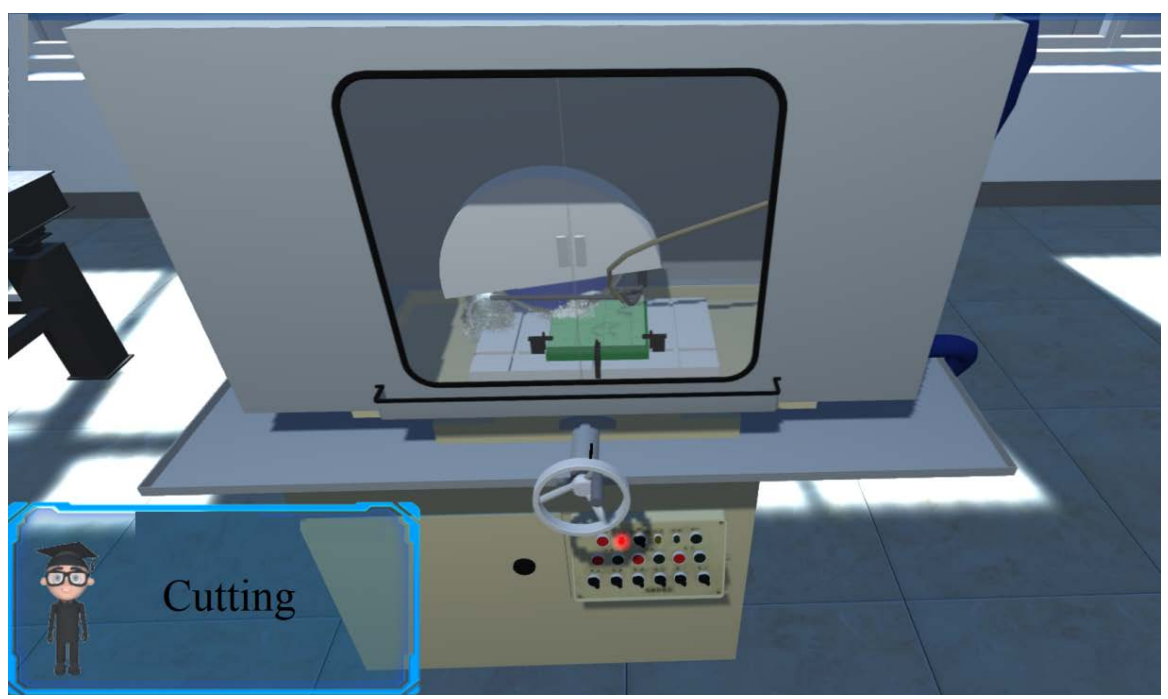

Figure 4. The Cutting process.

students will learn how to use spiral micrometer to measure the size of optical lens. So we set a virtual spiral micrometer in this experiment module, as shown in Figure 5. The virtual spiral micrometer has the same structure, function as the real spiral micrometer, which makes the student in a real learning environment.

\section{How to Use This Virtual Simulation Resource}

\subsection{How to Enter the Simulation System}

For this virtual simulation system, there are two ways to enter the simulation system. The first one is that the students can use their personal computers, which have the Windows operating system and more than $512 \mathrm{M}$ memory to do the experiments. The second one is that the students can use their personal intelligent mobile phones, which have the Android operating system and more than $512 \mathrm{M}$ running memory. For teachers, they can also use these ways to enter the simulation system. 

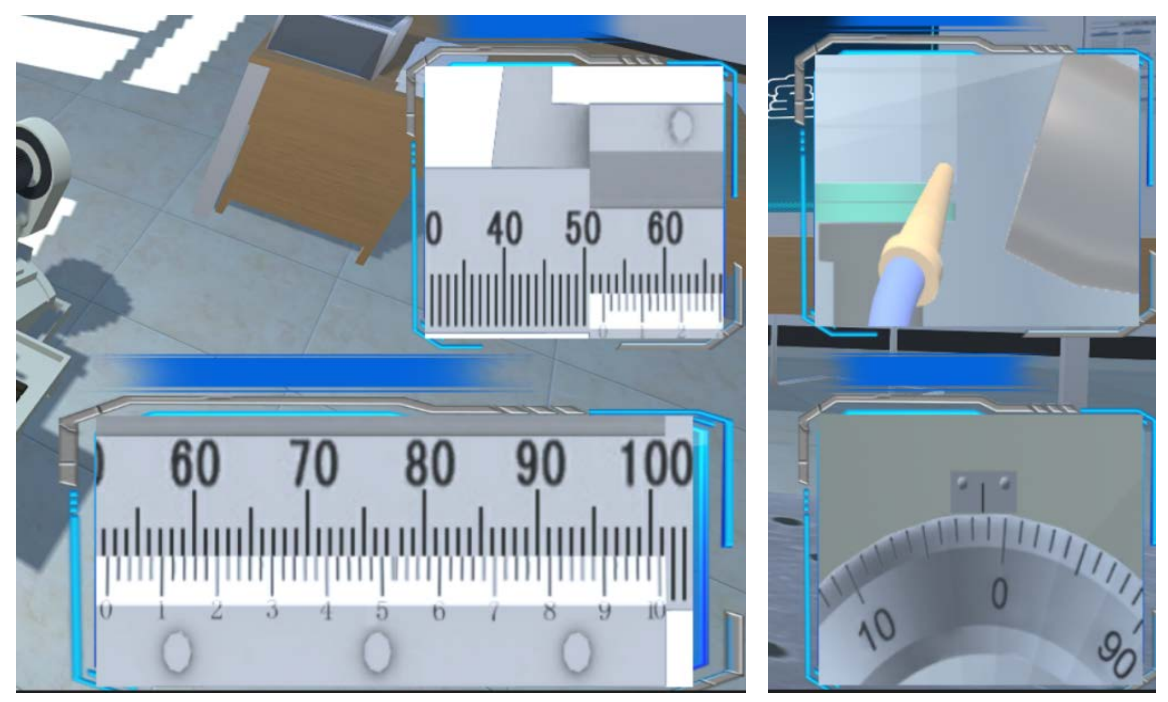

Figure 5. The virtual spiral micrometer.

\subsection{How to Assess Student Achievement}

The teacher arranges the preview content online for the students to prepare. Before experiment, the students are required to give the feedback about their preview. The teacher supervises and checks the students' preview. Only those, who pass the assessment, can carry out the next experiment. If safety problems are caused during operation, the student will get ZERO score.

\section{Conclusion}

For the traditional experiment, the teachers mainly focus on demonstration and how to operate. It is difficult to keep up with the step of new engineering construction and teaching reform. In this paper, we have designed the optical cold processing virtual simulation experiment teaching system. It promotes the popularization of applied optics, helps students to understand the theoretical knowledge learned at classroom. The students also can finish the high consumption, irreversible operation, and large-scale comprehensive training by the optical cold processing virtual simulation. It has strong practicability and significance for the experimental teaching reform. According to the teaching situation for several teaching cycles, the teaching effect is better than that for traditional experiment teaching way. For engineering and technical personnel, they can use this virtual simulation to enhance product design capability. So the virtual simulation experiments should be popularized.

\section{Acknowledgements}

This work was supported by School level key teaching and research project "International teaching reform under the background of integration of science and Education-Taking Optoelectronic Information Science and engineering as an example" (Project Number: 2019zd08); Exploration and practice of integrating "Laser Principles and Technology" into ideological and political education 
(Project Number: 2020zd04); Research on College Physics Curriculum Construction under the Background of Shandong New College Entrance Examination Reform (Project Number: M2021247, 2021dz02); "Reform and implementation of hybrid teaching mode of Higher Mathematics under the background of educational information age" (Project Number kczx202035).

\section{Conflicts of Interest}

The authors declare no conflicts of interest regarding the publication of this paper.

\section{References}

Cai, W. L., Walter, S., Karangelis, G., \& Sakas, G. (2000). Collaborative Virtual Simulation Environment for Radiotherapy Treatment Planning. Computer Graphics Forum, 19, 379-390. https://doi.org/10.1111/1467-8659.00430

Chen, P., Yang, T., Chen, X. X., Liu, Y. J., \& Chu, T. X. (2018). Intelligent Identification of Gas Anomalous Area by Electro-Magnetic Joint Exploration Technology. Journal of Engineering, 2018, 1645-1649. https://doi.org/10.1049/joe.2018.8293

Davis, A. (2015). Virtual Reality Simulation: An Innovative Teaching Tool for Dietetics Experiential Education. The Open Nutrition Journal, 9, 65-75.

https://doi.org/10.2174/1876396001509010065

Iwagami, H., Ishihara, R., Aoyama, K., Fukuda, H., Shimamoto, Y., Kono, M., Nakahira, H., Matsuura, N., Shichijo, S., Kanesaka, T., Kanzaki, H., Ishii, T., Nakatani, Y., \& Tada, T. (2021). Artificial Intelligence for the Detection of Esophageal and Esophagogastric Junctional Adenocarcinoma. Journal of Gastroenterology and Hepatology, 36, 131-136. https://doi.org/10.1111/jgh.15136

Krathwohl, D. R. (2002). A Revision of Bloom's Taxonomy: An Overview. Theory into Practice, 41, 212-218. https://doi.org/10.1207/s15430421tip4104_2

Notaroš, B. M., McCullough, R., Manić, S. B., \& Maciejewski, A. A. (2019). Computer-Assisted Learning of Electromagnetics through MATLAB Programming of Electromagnetic Fields in the Creativity Thread of an Integrated Approach to Electrical Engineering Education. Computer Applications in Engineering Education, 27, 271-287. https://doi.org/10.1002/cae.22073

Salto-Tellez, M., Maxwell, P., \& Hamilton, P. (2019) Artificial Intelligence-The Third Revolution in Pathology. Histopathology, 74, 372-376.

https://doi.org/10.1111/his.13760

Shen, Y., Yu, P., Lu, H., Zhang, X. L., \& Zeng, H. J. (2020). An AI-Based Virtual Simulation Experimental Teaching System in Space Engineering Education. Computer Applications in Engineering Education, 29, 329-338.

Yu, Y. L., Zhang, G. L., \& Zhang, H. Y. (2021). Exploration and Analysis on the Feasibility of VR Panoramic Technology Applied to Practical Training Teaching in Colleges and Universities. Advances in Applied Sociology, 11, 350-356.

https://doi.org/10.4236/aasoci.2021.118032

Zhao, C. L., \& Zhao, Y. N. (2019). Study on Business English Practical Teaching from the Perspective of Economics of Language. Creative Education, 10, 726-734.

https://doi.org/10.4236/ce.2019.104054

Zheng, W., Bai, Y. T., \& Che, H. X. (2018). A Computer-Assisted Instructional Method Based on Machine Learning in Software Testing Class. Computer Applications in Engineering Education, 26, 1150-1158. https://doi.org/10.1002/cae.21962 